\title{
Diabetes inside and outside of the body: a psycho- anthropological analysis of the treatment of "sugar disease" in Cameroon
}

\begin{abstract}
Diabetes, in addition to its deadly projections in developing countries, is a public health problem worldwide. This article attempts to highlight the link between the beliefs of the Cameroonian populations on diabetes and behaviors they tend to develop based on these beliefs. This metabolic disorder is then considered as a disease of the "biological body" because of chemical reactions taking place in the body of the individual, but also as a disease of the "social body" because it involves several social actors (health professionals, parents, patients, traditional therapists). By using social science research methods and a psychopathological approach, the authors attempt to show how patients, affected in their suffering and engaged in multiple health care trajectories including phytotherapy, sometimes find themselves involved into ritual practices, in order to prevent and cure the disease.
\end{abstract}

Keywords: diabetes, sugar, diet, metabolic disease, social disease, phytotherapy
Volume 5 Issue 2 - 2020

\section{Peguy Ndonko,' Nathalie Mbenda ${ }^{2}$}

'Doctor in Anthropology of Health, Research Laboratory in

Social and Medical Sciences for Development, Cameroon

2Psychiatrist, University Cheikh Anta Diop of Dakar

Acupuncture Detoxification Specialist NADA, South Africa

Correspondence: Nathalie Mbenda, Psychiatrist, University Cheikh Anta Diop of Dakar, Acupuncture Detoxification Specialist NADA, South Africa, Tel +23057536199,

Email nathalie.mbenda@gmail.com

Received: February 05, 2020 | Published: March 19, 2020

\section{Introduction}

Among noncommunicable diseases (NCDs), diabetes is, without a doubt, one of the most widespread NCDs in the world today. According to the IDF (International Diabetes Federation), the disease has already caused 4.2 million deaths. ${ }^{1}$ In Cameroon, in 2016, $2 \%$ of deaths that occurred as a result of diseases were attributed to diabetes. ${ }^{2}$ This disease has become in such a short time a real pandemic due to its strong progression in Africa in general and in Cameroon in particular. Diabetes is a group of metabolic disorders of multiple etiology characterized by chronic hyperglycemia ${ }^{1}$ with disturbances of carbohydrate, fat and protein metabolism resulting from defects in insulin secretion, insulin action (insulin resistance at the cellular level) or both. ${ }^{3,4}$

The incidence of diabetes is constantly increasing (108 million diabetic patients in 1980 against 422 million in 2014, and according to the 9th Diabetes Atlas published by the IDF in 2019, the estimate is currently increased to 463 million of individuals aged from 20-79 years), despite the active involvement of the pharmaceutical industry which is increasingly producing new molecules aimed at controlling the disease. One of the main reasons that could justify this dramatic increase in prevalence is the poor eating habits that people tend to adopt. However, this constitutes a modifiable risk factor. This biological disease (in the body) is at the same time considered as a social disease (outside the body), not only because of its significant and continuous spread, but also because of its ability to influence productivity and its impact on economy, starting at the family unit.

In addition, the means necessary for an early diagnosis of diabetes and the system of care required, challenges a whole system of social

${ }^{1}$ Fasting plasma glucose concentration above or equal to $7 \mathrm{mmol} / \mathrm{l}(1.26 \mathrm{~g} / \mathrm{l})$ or blood sugar greater than or equal to $2 \mathrm{~g} / \mathrm{l}$, taken at any time of the day, found twice, at different times. protections that the sociocultural perspective is aimed to balance. How do we understand the meaning of this sickness? What is the suffering that this disease impose on patients and their families? What are the therapeutic remedies used by people to alleviate their suffering?

\section{Study context and justification}

\section{Epidemiology}

Global age-standardised diabetes prevalence increased from $4.3 \%$ in 1980 to $9 \%$ in 2014 in men, and from $5 \%$ to $7.9 \%$ in women. ${ }^{5}$ In 2019 , worldwide prevalence is estimated to be $9.3 \%$. The geographic distribution of the disease shows that it is no more specific to developed countries (prevalence of $10.4 \%$ ). ${ }^{1}$ On the contrary, the prevalence of diabetes has increased faster in low income countries (4\%) and middle income countries $(9.5 \%))^{1,5} 79 \%$ of adults with diabetes are living in low- and middle-income countries and in Africa alone 19.4 million of people are living with diabetes, $60 \%$ of cases are undiagnosed and $73.1 \%$ of deaths due to diabetes occur in people under age of 60 years, compared to only $31.4 \%$ in Europe. ${ }^{1}$ These premature deaths reduces the workforce and has a negative impact in the economy as stipulated by Boomer et al. ${ }^{6}$ in their diabetes indirect costs estimation.

Diabetes is a major cause of many complications such as retinopathy and cataract (ultimately leading to blindness), kidney failure, sexual dysfunction, heart attack, stroke, diabetic neuropathy and lower limbs amputation. ${ }^{4}$ But one of the largest studies (pool of 628 ) in Cameroon has shown that the mortality of type 2 diabetes is high and most of the diabetic patients dies from acute metabolic complications $(22.2 \%)^{7}$ With this exponential rise, diabetes was already the 7 th deadliest disease in the world in 2016. ${ }^{8}$ According to new data from the IDF, ${ }^{1}$ the number of people with diabetes is expected to rise to 700 million by 2045 . These statistics are a real issue for global health system agencies and governments in many countries, which is why diabetes has become a major public health 
concern and is one of the four noncommunicable diseases targeted for priority intervention by health agencies. These figures also indicate an increase of the main risk factors of diabetes such as overweight or obesity, sedentarity and high blood pressure.

Globally, diabetes caused at least 760 billion US dollars in health expenditure in $2019-10 \%$ of total spending on adults. Africa is among the regions (second lowest) that spent the least on diabetes and for Cameroon in particular, total diabetes-related expenditure among adults (20-79 years) were estimated in between 50-200 million US dollars in 2019. ${ }^{1}$ Women in particular face multiple obstacles to access prevention, early detection, diagnosis, diabetes' treatment and health care at an affordable cost, especially in developing countries. 222.9 million of women are currently living with diabetes, which is a serious threat to the health of mothers and children since more deaths occurred in diabetic women (2.3 million) than in men ( 1.9 million). More than 20 million live births ( 1 in 6 births) are affected by hyperglycaemia during pregnancy- $84 \%$ having gestational diabetes-and the disease is associated with complications during and after childbirth. ${ }^{1}$

In Cameroon, the HoPiT (Health of Population in Transition Research Group) conducted the first epidemiological survey on diabetes in 1994, using internationally standardized methods. This group found that the prevalence rate varied between $1 \%$ to $9 \%$ for urban areas and $0.5 \%$ to $0.7 \%$ for rural areas, of which more women were affected than men in both areas. ${ }^{2,9}$ In 1997, the age-standardized prevalence of diabetes among men in rural areas $(0.9 \%)$ and the urban population $(0.8 \%)$ and among women in rural areas $(0.5 \%)$ and the urban population $(1.6 \%)$ was low, while that of impaired glucose tolerance was high $5.8 \%$ (rural) and $1.8 \%$ (urban) for men, and for women $2.2 \%$ (rural) and $2.0 \%$ (urban), which already indicated an early stage of a diabetes epidemic in Cameroon. ${ }^{10}$ Almost 10 years later, the HoPiT Research Group (2003) through a STEP ${ }^{3}$ subnational survey found a significant increase in the prevalence of diabetes $(6 \%)$, a high prevalence of some risk factors such as hypertension $(25 \%)$ and obesity ( $21 \%$ for women, $15 \%$ for men) and low awareness among the general population. Currently, the number of people suffering from diabetes in Cameroon is about 615300 cases according to the most recent figures of the $\operatorname{IDF}^{1}$ and the diabetes national prevalence (2079 years) is 5.2\% (4.4-6.4\%). These indices alerted decision-makers, leading to the recognition of diabetes as a public health problem in Cameroon

\section{Health care for diabetic patients in Cameroon}

Hospital care for diabetes is a reality in Cameroon. Most health facilities comprise endocrinology and diabetology units. Blood glucose tests and medical kits are mostly available. However, people complain about the relatively high cost of insulin, which remains a major obstacle to the success of treatment. Inaccessibility to medication could unfortunately lead to preventable complications, premature deaths and significant losses in terms of functional disability. Insulin and oral hypoglycemic drugs are still not available in sufficient quantities. Indeed, patients complain about the unavailability and sometimes the inaccessibility of these drugs: "the stock of drugs is sometimes limited, sometimes we do two to three months without treatment, sometimes we get our in refill in rural areas where stocks don't run out quickly".

${ }^{2}$ Source transmitted by Prof. Jean Claude Mbanya, HoPiT Research Group, Department of International Medicine and Specialties, Faculty of Medicine and Biomedical Sciences of Yaoundé, University of Yaoundé I.

${ }^{3}$ Statistical Education Through Problem Solving.
From these observations, it seemed relevant to us to conduct an anthropological study on the problem of diabetes also known as the "silent killer", in order to understand what, in human behavior, could foster the increase in the incidence of this pathology. To this study, we joined a psychopathological analysis in order to understand how the diabetic patient lives and how he could mentally processes his state of sickness from the announcement of the diagnosis to the stage of complications.

\section{Study area, materials and methods}

This study is the result of the work of several research seminars, conducted at the Cabinet "Psycause Cameroun", in an urban environment of the city of Yaoundé. Psycause is a Research Laboratory in Social and Medical Sciences for Development, a joint research unit in psychiatry and mental health. This research firm also serves as a center for reception, consultation and treatment of diabetes with natural medicine. Cameroon is home to more than a hundred hospital institutions, among which there are major diabetes reference centers such as the University Teaching Hospital of Yaoundé, the Central Hospital of Yaoundé, the General Hospital of Yaoundé and several other health facilities which undertake the management of diabetic patients. This is a qualitative, descriptive and analytical study. The survey for the data collection for this study started in 2013 and kept going until 2019. The data collection techniques used to conduct this study include: one-on-one interviews (with patients identified during seminars and blood tests); clinical interviews (with seminars participants who have disclosed their diagnosis), focus groups (with diabetic patients identified during seminars) and finally patients life stories. The participants gave their consent on which we guaranteed their anonymity. Social representation theory has been used as a method to define people's perceptions of this disease.

The first seminar in 2013 had 104 participants including 98 diabetics. The second seminar in 2015 had 122 participants including 109 diabetics, four laboratory technicians who came from the city of Douala to carry out tests free of charge to participants, the other nine participants were made up of parents and people interested in this topic. Among these 109 diabetic patients, some participants of the first seminar who continued to come to the center for their follow-up were present.

Both seminars took place in a large hall. Focus groups were held a few weeks after the seminar in a smaller space. Three discussion groups were created to mobilize the majority of seminar participants. Groups were made up of 6 to 12 people. We met the participants at several occasions. A group of diabetes peer educators was created within the laboratory to support new patients and to educate families about the disease. Patients who came back to refill phytotherapeutic drugs for diabetes were also followed up regularly.

\section{Diabetes in the body}

\section{The origins of diabetes or "sugar disease", according to populations}

Diabetes is recognized and named in almost all languages of Cameroon. Among the Bassa in the Central region, diabetes is called "konbömbô" and means "sugar disease". Thus a Bassa from NyongEkelle will say "mé konbömbô" to indicate that he is diabetic or even "mé kômkôn binainai". Beti in central Cameroon designates sugar by the term "mikog" and disease by "oukon". Sugar disease or diabetes 
is called "oukonmikog". Among the Bamiléké of the West Cameroon region, the disease is named "ngoukat", that means "something that wanders, which can spread", and sugar is called "ndimte"; diabetes is therefore the disease of the sweet thing: "ngoukat ndimte". These examples of diabetes terminology illustrate popular representations of diabetes. Indeed, for the general population, the onset of diabetes is linked to the excessive consumption, by an individual, of the sugar contained in certain foods. This very strong belief does not necessarily take into account the amount of insulin produced by the body, its availability, or its action on metabolism of carbohydrate, lipid or protein as explained by the pathophysiology of diabetes. ${ }^{3}$ But deductively, their belief is based on the disproportion between the amount of sugar consumed by an individual and what the human body is able to absorb or metabolize.

According to the people interviewed, this disease could originates from the excessive consumption of sweet foods. Ms. J, 54, living in Yaoundé, recognizes the origin of her illness in these terms: "I know the origin of my illness, I used to eat a lot of sweet things, so when I am told that it is [because of] sugar, I do not doubt. My husband used to tell me to be careful with sugar. I could finish a can of sweet milk by spreading on the bread. As we had a shop, everyday, I used to eat chocolates, I used to drink three to four bottles of sweet juices, each day. I took candies when I was cold. Yes, I myself looked for this illness! I just want to be treated because I'm already tired of going to the hospital, nothing changes...".

Like this lady, as soon as the link between diabetes and excessive sugar consumption is made, there is an awareness that pushes patients to avoid this type of food or to reduce their consumption. However, this measure only focuses on quick-acting sugars, what is commonly called "sweets", including plain sugar, sweet treats, desserts, fruit juices and sugary soft drinks. Slow-releasing sugars or complex carbohydrates: starchy foods, cereals and glycogen of animal origin are not considered harmful by populations and their consumption is not particularly avoided or reduced. However, if consumed in large quantities, they can lead to weight gain and induce insulin resistance. Indeed, the mechanism of insulin resistance which is strongly linked to metabolic syndrome, obesity and especially visceral adiposity ${ }^{11}$ is not clearly perceived by the populations. Because of lack of knowledge, even if sugary foods are sometimes avoided, populations do not refrain from consuming foods rich in lipids, and are therefore exposed to significant weight gain which increases the risk of developing type 2 diabetes.

According to epidemiological data, diabetes is a steadily increasing disease in the majority of the countries of the world. This constant rise can be explained from an environmental perspective by the deterioration of eating habits in our "consumption society", and this from an early age. Mbanya et al. ${ }^{10}$ refer to it as an "adoption of Western lifestyles", among which we can mention an unbalanced diet, rich in carbohydrates and fats, the unconscious and excessive consumption of fast food, the proliferation of food components of questionable quality (containing chemicals) and available at low prices. Poor eating habits (including snacking), sedentary lifestyle (with a more urban lifestyle) also contribute to the progression of diabetes. Yet these risk factors can be changed through preventive education, among other measures (Figure 1).

${ }^{4} \mathrm{All}$ of the patient testimonies in this article were originally written in French and then translated into English by the authors.

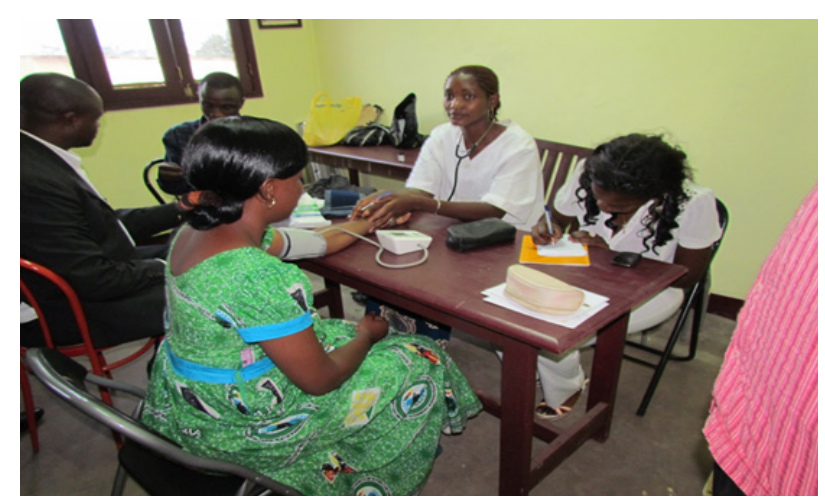

Figure I This photo was taken in 2013 during a diabetes awareness seminar at the headquarters of 'Psycause Cameroun', in Yaoundé. Laboratory workers came from Douala to check participants' blood sugar. They also took blood pressure and weighed patients free of charge. Photo source: Peguy Ndonko

\section{Scientific evidence or popular belief?}

Diabetes is a metabolic disease characterized by a permanent alteration in the metabolism of carbohydrates which are not correctly used by the body. Such an alteration is mainly due to a lack of insulin or a deficiency in the action of insulin, a hormone secreted by the beta cells of the islets of Langerhans of the pancreas. Its fundamental function in the organism is to enable the metabolism of carbohydrates, to take part in the process of glycogen synthesis and allow storage in this form in the liver and in the muscles, to promote oxidation and combustion of glucose in the tissues, especially in the muscles, and finally to prevent the transformation of proteins and fats into carbohydrates. ${ }^{12,13}$ The dominant clinical signs of a diabetic condition are the consequence of two characteristic biological signs which are hyperglycemia and glycosuria. Carbohydrates, like all nutrients, are subjected in the body to new processes of separation, disintegration, development, transformation and synthesis. Diabetics therefore lack the organic capacity, following insulin insufficiency or resistance to its action, to metabolize-meaning to use efficiently-all carbohydrates. As a result of this malfunction, sugars accumulate in excessive amounts in the blood (hyperglycemia) and are then eliminated with the urine (glycosuria).

According to Saporano, ${ }^{12}$ the first cause of diabetes is the individual constitution. Diabetes can then be considered a "constitutional" disease. In fact, the disease can manifest itself entirely spontaneously from childhood, independently of any recognizable and individualized external pathogenic factor. This constitutional predisposition results in a congenital weakness of the endocrine pancreas, more vulnerable to pathogens like viruses as in the case of type 1B diabetes, ${ }^{14}$ or prone to the development of immunological processes as is the case for type $1 \mathrm{~A}$ diabetes. ${ }^{15}$ In addition, the pancreas, when subjected to considerable activity, inevitably goes beyond its capacity and becomes exhausted. As a result, in individuals whose endocrine function of the pancreas is already congenitally weak or at the limits of its sufficiency, diabetes can easily occur.

Cameroonian populations who do not know this metabolic description most often attribute the cause of the disease to witchcraft, a curse inflicted on the child or an attack of an evil spirit, because, in their reasoning they are trying to understand "how a child who was born not long ago would have already consumed that amount of sugar?" From this observation, most often people resort to divination to look for the origin and the meaning of the evil illness. It is therefore 
necessary, even essential, to educate families about this pathology Education of populations must be part of health care alongside medical treatments in order to modify population's knowledge pertaining to this disease. Diabetic patients are aware that their disease is the result of high blood sugar. As soon as they are informed of their status, they avoid consuming sugar cubes (white sugar) which, according to popular imagery, is the first food that causes the disease. They also avoid consuming carbonated drinks, which are said to contain a lot of sugar. Hyperglycemia is often manifested by constant fatigue, intense thirst and sometimes by a crisis that ultimately pushes them towards taking medication such as insulin. Some patients who attended the seminars claimed they did not tolerate insulin injections. They believe that this substance that is injected into the body could cause severe or even fatal anemia. Most diabetics have a glucometer that allows them to take their blood sugar by themselves. This practice of selfmonitoring is common but remains limited for patients from rural areas and those less educated who do not understand the operating instructions of the device or tend to forget easily. Thus, some people rely to health centers and pharmacies close to their place of residence in order to get their blood sugar measured periodically.

\section{Diabetic patients disease's experience}

\section{Diagnosis announcement and patients disease experience}

Diabetes is a chronic disease which can have a fatal outcome following complications of acute onset (hypoglycemic coma, hyperosmolar coma...) or due to chronic deterioration of vital organs (heart, kidney...). Due to its genetic predisposition, diabetes can impact future generations. This inherited vulnerability associated to environmental factors-mainly poor habits-could lead to the resurgence of the disease (in the family tree) which can possibly have a fatal outcome. Thus, for the Cameroonian population, diabetes remains a permanent concern and has a significant psychological impact. In addition, popular imagery does not help improve this dramatic view of the disease. The threat of diabetes and its potentially fatal outcome may seem like a death sentence to patients, especially when the diagnosis is announced, when they live in precarious conditions, given the lack of medical follow-up, ignorance of the nature of the disease and poor lifestyle.

It is the fear of dying, the anxiety at the announcement of the diagnosis and the distressing experience of the disease (and its complications) which come up from the following speeches:

"When I was informed that I am diabetic, I started thinking of my mother who also died from diabetes at the Yaoundé Central Hospital, I thought that my life was over, I will follow my mother to the grave, since I was told at the hospital that there is no cure for diabetes, that we live with the disease until death. My feet were frozen on the ground, I sighed from time to time. A lot of things were going on in my head, I was thinking to whom I will leave my children with, I saw how people are going to kill them and drive them out of the house to sell my land, my head was getting bigger. But since I started taking natural medicines, I have a lot of hope, my weight has gone back to normal. I am no longer drinking 10 liters of water a day, my clothes are no more tight on me, people are telling me that I have changed, that I am still very beautiful". Mrs. M, 48 years old, diabetic patient, Yaoundé.

"I have a very bad idea of diabetes. One day at the Biyem Assi Hospital, I was looking after a patient. A woman told us that her daughter died from diabetes because the nurse placed the drip on her without controlling her blood sugar and soon after, her daughter turned her eyes as a sign of departure and she died some time after. I started to be afraid of this disease and even to go to the hospital, because I don't understand how someone is sick and runs only to die in the hospital where he wanted to be safe. It's good to have meetings like this all the time to inform people, it was very insightful." Mr. B, 27 years old, seminary participant, Yaoundé.

Diabetes, in addition to its known physical complications, can have many repercussions on the mental and emotional health of people who suffer from it. As soon as the diagnosis is announced, patients may experience anger, frustration, sadness or even denial, especially since they understand the long-term impact of this chronic disease, which happens to be the source of multiple and serious complications. Intolerance of the status of "the sick person" joined to the image of a "person diminished by the disease", of little use to his community, can evolve towards a real devaluation of oneself or of his capacities, especially in people who were very active before or those who received insufficient counseling and support. These emotional states, this devaluing self-perception, and above all the double loss-real and symbolic-of a previous state of good health can evolve, if they are not recognized and addressed on time, towards a depressive state.

\section{Therapeutic practices and phytotherapy}

According to our survey, the majority of diabetes patients goes to a health center to get their medications. However, some complain about the high cost and the side effects of these drugs. Mr. X..., 33 years old, in Yaoundé, narrates: "I'm going to tell you about my case. A friend of mine told me about natural medicine to treat diabetes. I hesitated a lot, I took all my time, confused, I didn't want to go to the hospital anymore, I was suspicious of quacks. One day, when illness had taken me over, I came here. I had no strength to go upstairs, I called on the phone and they came to get me downstairs. I was out of breath, coughing badly, salivating. I had injuries, three injuries on the backside. I paid for three months of treatment and three different medications and was given natural medications, one for drinking, the other for licking and another one to apply on my wounds. But, a few days later, I felt relieved and my wife said to me: "I see that there is change, you are not that tired anymore, it will be fine". After a while, I saw that my blood sugar has dropped, from four to two, I just drank the remedy as much as I could! (...) I came to tell people that it is true, we can treat diabetes".

Ms. SN, 27 years old, says: "My illness prevents me from continuing my studies. I'm never in good shape. They even changed my insulin and prescribed another stronger and more expensive one. I do not know who to turn to. I felt obliged to stop my studies to work in order to have some money for my health care, my parents couldn't take it anymore. When I have no money, I skip the treatment and I am sick all the time, I have no more life, I only wait for death (sobbing) ..."

Stress during therapeutic follow-up is frequent, it could be the result of potentially stressful new behaviors like taking a regular blood sugar measurement; which requires special training at the start, when you have to do it yourself with a device for personal use, or even a budget allowance in case you need to go to a health center or a pharmacy to take the test. Secondly, the control of nutritional intake -n quality and quantity-and the precise dosage of drugs, insulin injections for instance, require effort and discipline which the patient 
must now integrate into his daily routine. The same goes for the measures to be taken to prevent complications. This learning process can therefore generate additional stress especially at the beginning when the diagnosis is announced and when a lifestyle change occurs. Financial difficulties greatly influence the patient's therapeutic course and the treatment follow-up. According to the testimony of Ms. SN, the lack of financial means forced her to seek treatment with herbal medicine. ${ }^{5}$ At first, her fasting blood sugar was $4.14 \mathrm{~g} / \mathrm{l}$, then she followed a treatment based on medicinal plants. After 30 days, she checked her blood sugar and the level had dropped to 1.92g/l. During the second month, while taking the same decoction her blood sugar went down to $0.60 \mathrm{~g} / \mathrm{l}$. At her three-month checkup, she realized that her blood sugar remained stable. We contacted the laboratory where she was doing her medical tests to have the history of her samples and the duplicates we received confirmed her statements.

Herbal therapy may be less costly for patients without means and easier to administer than multiple insulin injections or multiple doses of daily oral anti-diabetic drugs. A type 2 diabetic pays an average of 60,000 francs (just over USD 100) for three months of treatment. The ease of administration and the relatively low cost of herbal medicine encourage some patients to use it more. The other benefit of these herbal medicines could be their holistic nature. In addition to balancing the blood sugar level, they would provide nutrients to the body and other benefits such as positive effects against stomach ache, pancreatic stones and anemia. Patients with a blood sugar level above $2 \mathrm{~g} / 1$ alternate between pharmaceutic medication and herbal medicines. In this perspective, blood sugar control is very strict and is done several times a week. For patients whose blood sugar level is regularly below $2 \mathrm{~g} / \mathrm{l}$, they are advised to stop taking their pharmaceutical drugs but rather continue with only herbal medicines. However, the long-term impact of stopping the pharmaceutical drug under these conditions has not been yet the subject of a large-scale study (Figure 2).

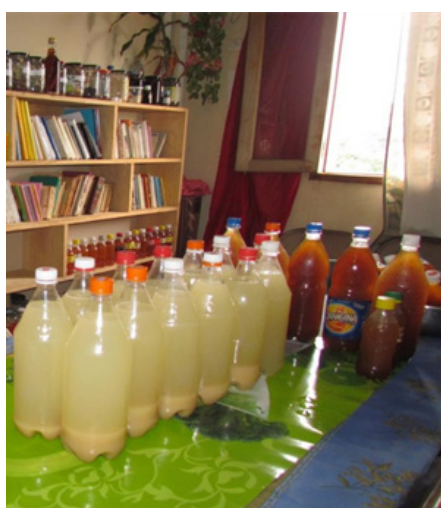

Figure 2 Herbal medicine (Diastop 2) for the treatment of diabetes. Photo source: Peguy Ndonko

Diabetic patients who take this herbal medicine and do not respect the instructions or the food/drug prohibitions have their blood sugar level increase, as a matter of fact they immediately experience asthenia, dizziness and diaphoresis. Ms. X..., a 45-year- old diabetic patient, living in Yaoundé, says: "Since last week, my blood sugar had dropped, but when I went to mourn in the village, I drank a bottle of soft drink and I fell. The following week, I went from $2.40 \mathrm{~g} / 1$ to ${ }^{5}$ These phytotherapeutic drugs called "Diastop1" and "Diastop2" are in the form of a decoction to be drunk. The treatment lasts between one and three months Research on the actual efficacy and possible toxicity of the product is underway.
$1.88 \mathrm{~g} / 1$. Yesterday I took an effervescent calcium tablet because I was feeling tiredness on my legs. I went back to $2.80 \mathrm{~g} / 1$. I didn't know that I shouldn't take this medicine when I am diabetic.'

It appears from this testimony that the patient did self-medication, without the advice of her practitioner by taking a tablet of calcium which contains sugar. She wanted to treat an underlying symptom of diabetes. However, during counseling, patients are reminded not to take any other medication during treatment without the advice of their caregiver. Whether in hospital or during herbal therapy, patients receive education aimed at improving their dietetic and hygienic habits, as well as information concerning their therapeutic follow-up.

\section{Complications, an additional weight}

The diabetic people surveyed mentioned known complications. Regarding blindness, the testimony of Mr. X..., 65 years old, stood up: "My son, I have been diabetic for several years, at one point, I had vision problems and I was operated on both eyes in France. Finally, I no longer see, I am blind. Afterwards, I was told that I am going to undergo ear surgery because I can't hear well anymore. I couldn't accept to be buried in pieces. One day God inspired me and I got to know someone who treats with herbal medicines and that really relieved me. Now I can at least walk with a stick, I eat well..."(Figure 3) "When you get to the diabetic ward of the hospital, you understand that human life is nothing. You look over there, you see someone whose foot has been cut off, you look on the other bed, you see another one whose both feet were cut off, you look, you see a third one with a bandage on his foot and he is about to have the foot cut off the next day. Then they take someone in front of you, the next day you realize that he no longer has his foot, they cut it off and sent him home to buried. Diabetes causes people to be buried in pieces." Mr. E, 32 years old, participant, Yaoundé

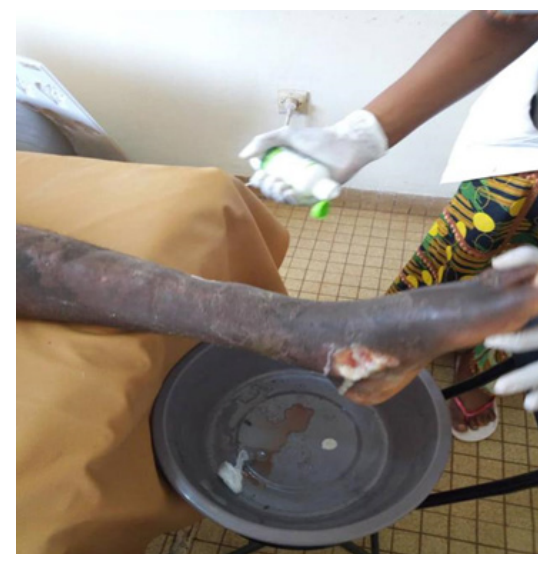

Figure 3 Foot wound on a diabetic patient. Photo source: Anaba

Diabetes induces the development of furunculosis and wounds including pressure ulcers and diabetic foot (40-60 million people globally). ${ }^{1}$ These wounds which are difficult to heal are commonly called "incurable wounds". It seems obvious to the nursing staff that the removal of the affected limb is the only suitable option, but this amputation is apprehended with fear, pain and uncertainty by the patient, especially if the announcement of this surgical intervention is brutal. Indeed, the patient has the impression of being buried in pieces or in "spare parts". Studies show that the mortality rate for amputees is high, the median life expectancy is less than 2 years and only $5 \%$ of elderly amputees become fully independent as reported 
by Sinclair and Croxson. ${ }^{16}$ Similarly, Beyaz et al. ${ }^{17}$ found a low life expectancy $(<3$ years) for patients who underwent an amputation below the knee. Perception of the attack on his physical integrity could be felt with harshness by the patient and could affect his psychic representation and his mental image of himself. It can give rise to a feeling of depreciation of one's own person, of incompleteness or even a rejection of one's new image (after surgery). The experience of depression could also emerge from the feeling of loss of a part of oneself, of one's physical integrity and of one's productivity. Hence the importance of a psychological support throughout the process.

Diabetes, in the long run, affects the vital organs: the heart, the brain, the kidneys which are of capital importance for the functioning of the organism but it also targets the organs of locomotion like the lower limbs, which have a significant value with regard to the functionality of the individual since they serve to his mobility, through which he can perform his duties, earn a living and have a sense of independence. The prevention of complications such as the diabetic foot requires education of the patient, who will have to learn to wear adequate shoes, to examine his feet thoroughly, in search of any abnormality that his sensitivity would not have perceived, and finally to perform regular visits to the podiatrist. Given the speed with which infections spread in the diabetic patient, these preventive precautions could occupy an important place in the life of the patient who wants to ensure his physical integrity and who wishes to maintain a professional activity or an occupation as long as possible. The apprehension of the loss of one of its limbs can therefore be seen as a threat and become a source of anxiety.

\section{Diabetes outside the body}

\section{Diabetes as a social burden and a discriminator}

When Sontag ${ }^{18}$ speaks of illness being a metaphor, she means that through the ills it causes, it affects man psychologically, emotionally or even shows the socio-economic status of the patient, his family and even his society. Keuky ${ }^{19}$ exposes the case of patient Sokhann in Cambodia whose income did not allow her to take care of herself when she was diagnosed with type 2 diabetes in 1997. For more than ten years, she lived with diabetes without treatment, education or monitoring. Attending a diabetes clinic and purchasing diabetes medication was far beyond her family's means. In this way, diabetes, on a biological level, has an important medical dimension, but it is also a social disease because it influences the choice of the therapeutic trajectory of the patient, makes it possible to understand the type of society where the disease occurs and helps in analyzing the health care system put in place as well as the medical institutions involved in its fight.

Djouda Feudjio ${ }^{20}$ illustrates the above statement with this observation of patients in the African context: "Many patients in Africa do not have real autonomy in the choice of their trajectory. The illness of an individual involves the members of his sociofamily circle. The followed therapeutic trajectory may not be the one desired by the patient, but that was chosen by his relational network. Therapeutic choices are therefore not always made by one person nor isolated, they have a history and are determined by a family 'hiatus' or by the socio-family balance of power". ${ }^{6}$

The observations that this author has noted on the disruption of health care trajectories have strengthened his standpoint on health care places in Cameroon. Socpa and Djouda Feudjio ${ }^{21}$ deplore that

\footnotetext{
${ }^{6}$ Courtesy translation by the authors. Quote originally written in French.
}

"the deviant practices and dysfunctions observed in the Cameroonian medical field make it a real space of conflict between the actors. If health care has this particularity of including a relational network, involving at the start the gathering and the presence of actors, it should be emphasized that the Cameroonian patients deprived of financial, cultural or symbolic capital are experiencing strenuous relationships of care".

Diabetic patients, regardless of their gender, are subject to all kinds of discrimination. Women may be constantly tired and unable to exert great effort. Mrs. KM, a 43-year-old widow with diabetes says: "I can drink 10 to 20 liters of water a day and go to the bathroom every five minutes. I take shots of insulin three times a day. I realize that I am a burden on my children and my family. It bothers me a lot. It is at the death of my husband that I was diagnosed with diabetes. I have been living with this bad disease for 13 years, I wish I had a disease other than diabetes..." If the work capability of women is reduced, they can become a burden on their families who are almost obliged to provide for their daily nutritional needs and health care, in addition to providing them with psycho-emotional support. This loss of autonomy could be a difficult experience for the patient. However, the elderly person in the African context, and by extension the parent, should always be exalted to a special status in front of his descendants and his collaterals. The situation of living with a chronic illness can lead to a feeling of chronic vulnerability and put the mature person in a situation of weakness, dependence and therefore loss of power, in particular loss of decision-making power.

This disease puts couple life at risk in the sense that a significant number of diabetic men complain of erectile dysfunctions, which can go as far as the total loss of the erection. Genitourinary disorders and sexual dysfunction in diabetes can be the result of vascular and neurological dysfunction or even an infectious problem. Mr. NJ, a 46-year-old diabetic patient, expresses his dismay as follows: "It is a permanent danger for a man who has lost his sexual capacity. I am sorry for my wife because I imagine what she feels, what she is missing. [Doctors should] really think about finding a solution to our problems, you would have saved many families." The value of sexuality in a couple is well proven. And when sexual activity is not experienced to the satisfaction of both spouses, it can affect the wellbeing of the couple. More specifically, the patient feeling devalued and guilty could consider himself weak or inefficient towards his partner.

\section{Diabetes: an inherited or a cultural disease?}

In Cameroon, opinions are divided on the recognition of diabetes as a hereditary disease and on the possibility of a treatment. Part of the population believes that medications only help improve patients health and stabilize the disease. They live in expectation of a cure that will not happen. Others have more confidence in the treatment and accommodate themselves to the idea of living with the disease, such as Mr. JK, a 48-year- old diabetic patient who says: "I have been diabetic for a long time and my mother was also diabetic, she died at the age of 79 and it was not diabetes that killed her. We are many in the family living with diabetes and this is no longer a problem for any of us. Our ancestors have long lived with this disease, I don't know why it kills a lot today." We noted above that diabetes can lead to complications such as memory loss, chronic fatigue, furunculosis and wounds. These signs and symptoms are often mentioned by the patients during interviews. They are interpreted in the Bamiléké culture (people of West Cameroon) as a call, a reminder to return to

${ }^{7}$ Courtesy translation by the authors. Quote originally written in French. 
the ancestral cultural values. Diabetes, although known to the medical public in its biological aspects, also has an ethnological dimension which is important to understand. Indeed, diabetes through the wounds it causes is a "revealing disease". It brings the sick individual back to his cultural identity, to the settlement of debts to the ancestors.

Diabetic wounds refer the patient to his cultural beliefs and practices related to health. The Bamiléké of Cameroon speak of "Fâ". Here, it is the "Fâ" related to physical wounds, which is different from the "Fâ" related to the death of a person after a drowning, traffic accident or suicide with bloodshed. The "Fâ" occurs here when the individual has gone through a foot amputation or has bloody wounds. According to the beliefs of this culture, the diabetic person who dies with wounds or amputated legs is impure for his family and this impurity can be traced back for several generations. Diabetes, through its complications, is part of the "group diseases" also called cultural diseases. Group diseases are those that affect several people in the same family and persist over an entire generation. In the Bamiléké context, group diseases are designated by the term "Fâ", which means "to shed blood". The situations which expose an individual to "Fâ" are for instance a crime with bloodshed, committed by a third party of which the individual was a victim during war, bloodshed through an accident, falling from a tree or anytime that a person dies with wounds on his body. A diabetic patient which present a wound or has gone through amputation is a carrier of the "Fâ". If he dies without being able to heal his wound, he thus transmits the "Fâ" to his progeny. Like many socio-cultures of Cameroon, among the Bamiléké and more specifically among the Bangangté (subgroup of the Bamiléké ethnic group), the "Vereh" ritual can be performed to prevent and annihilate the circulation of the disease between family members.

Science through biology and genetics explains and justifies the hereditary nature of diabetes, as a disease with a genetic predisposition, but according to the Bamiléké cultural reference, it is rather through the appearance of one of its complication-which involves bloodshed resulting to a state of symbolic impurity-that the disease could affect other people of the same lineage and this over several generations. Could the same observation be the starting point of two different explanations and interpretations? The observation that diabetes is a group disease which can affect several members of the same family and extend over several generations.

\section{Conclusion}

It emerges from statistical and epidemiological studies that diabetes is a group of chronic disorders with a genetic predisposition. Described as a "silent killer", diabetes is in constant progression in the majority of human societies. Despite the efforts of the public authorities and the preventive and curative measures implemented by health institutions, the progression of this disease is intensifying. The progression of type 2 diabetes can be justified by an unhealthy diet and unhygienic habits adopted by our societies which have become very consuming. Such an unbalanced diet, too rich in carbohydrates and fats, leads to overweight and ultimately to insulin resistance. Likewise, the sedentary lifestyle and the lack of physical exercise also promote significant weight gain. Patients follow multiple and diverse therapeutic routes, each according to their socioeconomic status and the belief system that derives from their cultural and religious identity. This is why phytotherapy can sometimes take over from oral anti-diabetics or insulin recommended by the pharmaceutic industry and conventional medicine. The disease can also be perceived as a cultural disease, which brings about a return to traditional values, and encourages individuals to strengthen their sense of belonging to the lineage of their ancestors through rites.
As Saponaro ${ }^{12}$ puts it: "Diabetes is not an incurable disease, in any case, impossible to treat". The course of the disease can stabilize if the patients opt for an appropriate medical follow-up, which takes into account in addition to the biological dimension, a psychosocial dimension. In fact, since it is a chronic disease that provides many complications, patients and their families must be accompanied to avoid situations of stress, anxiety or depression. Controlling the parameters of this disease and even its progression will undoubtedly involve efforts in the field of public health and multidisciplinary research, in order to reduce the loss of human life and loss in terms of workforce and productivity. ${ }^{22}$

\section{Acknowledgments}

None.

\section{Conflicts of interest}

Author declares that there is no conflict of interest.

\section{Funding}

My research project was not partially or fully sponsored by any institution.

\section{References}

1. International Diabetes Federation. IDF Diabetes Atlas Ninth edition 2019. 2019 .

2. World Health Organization. Diabetes country profiles. 2016.

3. World Health Organization. Definition, diagnosis and classification of diabetes mellitus and its complications: report of a WHO consultation. Part 1, Diagnosis and classification of diabetes mellitus (No. WHO/NCD/ NCS/99.2). Geneva: World health organization; 1999.

4. American Diabetes Association. Diagnosis and classification of diabetes mellitus. Diabetes care. 2009;32(Suppl 1):S62-S67.

5. NCD Risk Factor Collaboration. Worldwide trends in diabetes since 1980: a pooled analysis of 751 population-based studies with 4.4 million participants. The Lancet. 2016;387(10027):1513-1530.

6. Bommer C, Heesemann E, Sagalova V, et al. The global economic burden of diabetes in adults aged 20-79 years: a cost-of-illness study. The lancet Diabetes \& endocrinology. 2017;5(6) :423-430.

7. Foryoung JB, Ditah C, Nde Fon P, et al. Long-term mortality in outpatients with type 2 diabetes in a reference hospital in Cameroon: a retrospective cohort study. BMJ open. 2018;8(2):e019086.

8. World Health Organization. Global Health Estimates 2016: Deaths by Cause, Age, Sex, by Country and by Region, 2000-2016. Geneva: World health organization; 2018.

9. World Health Organization. World Report on Knowledge for Better Health: Strengthening Health Systems. Geneva: World Health Organization; 2004. $111 \mathrm{p}$.

10. Mbanya JC, Ngogang J, Salah JN, et al. Prevalence of NIDDM and impaired glucose tolerance in a rural and an urban population in Cameroon. Diabetologia. 1997;40(7):824-829.

11. Hardy OT, Czech MP, Corvera S, et al. What causes the insulin resistance underlying obesity? Current opinion in endocrinology, diabetes, and obesity. 2012;19(2):81-87.

12. Saponaro A. Comment soigner le diabète? Paris: Éditions De Vecchi; 1983.

13. Wilcox G. Insulin and insulin resistance. The Clinical biochemist Reviews. 2005;26(2):19-39. 
14. Urakami $\mathrm{T}$, Inami I, Morimoto $\mathrm{S}$, et al Clinical Characteristics of NonImmune-Mediated, Idiopathic Type 1 (Type IB) Diabetes Mellitus in Japanese Children and Adolescents. Journal of pediatric endocrinology \& metabolism. 2002;15:283-288.

15. Piya A, Michels AW. Understanding the immunology of type 1 diabetesan overview of current knowledge and perspectives for the future. US Endocrinology. 2012;8(1):70-74.

16. Sinclair AJ, Croxson SCM. Chapter 92-Diabetes Mellitus. Brocklehurst's Textbook of Geriatric Medicine and Gerontology (7th Edition). Philadelphia: WB Saunders; 2010. p. 760-774.

17. Beyaz S, Güler ÜÖ, Bağır GŞ. Factors affecting lifespan following belowknee amputation in diabetic patients. Acta orthopaedica et traumatologica turcica. 2017;51(5):393-397.
18. Sontag S. La maladie comme métaphore. Paris; 2009.

19. Keuky L. Pauvreté abjecte, difficultés majeures et issues tragiques au Cambodge. Diabetes Voice, numéro spécial. 2009. 54 p.

20. Djouda Feudjio YB. Trajectoires thérapeutiques des malades de la tuberculose au Cameroun: une analyse à partir des réseaux relationnels. In: Nkoum BA, editor. Santé plurielle en Afrique: perspective pluridisciplinaire. Paris: L'Harmattan; 2011. p. 317-336.

21. Socpa A, Djouda Feudjio YB. L'Hôpital au Cameroun: lieu de soins ou espace conflictuel? In: Nkoum BA, editor. Santé plurielle en Afrique : perspective pluridisciplinaire. Paris: L'Harmattan; 2011. p. 337-359.

22. Health of Population in Transition Research Group. Cameroon Burden of Diabetes Project: Baseline Survey Report Summary. 2004. 